\title{
Transmission Electron Microscopy Yields Clues to Platinum Particle Growth Phenomena in Fuel Cell Electrodes
}

\author{
J.R. Mawdsley, X. Wang, and D. J. Myers
}

Chemical Engineering Division, Argonne National Laboratory, Bldg. 205, 9700 S. Cass Ave., Argonne, IL 60439

Polymer electrolyte fuel cells (PEFC's) are of great interest for both transportation and stationary applications because of their low operating temperatures $\left(80^{\circ} \mathrm{C}\right)$ as compared to other types of fuel cells. PEFC's typically use carbon supported platinum catalysts in their electrodes to promote the chemical reactions that generate electrical energy. PEFC performance loss under steady-state and cycling conditions has been attributed in part to a loss of electrochemically active surface area of the platinum cathode electrocatalyst [1]. One of the proposed mechanisms for the loss of electrochemically active surface area is oxidation and dissolution of platinum at the high potentials typical of the PEFC cathode [2]. This dissolved platinum can then either deposit on existing Pt particles to form larger particles [2] or diffuse into an electrochemically inaccessible portion of the membrane-electrode assembly [3]. Our group has been studying the long-term dissolution and degradation behavior of polycrystalline platinum and high-surface-area carbon-supported platinum particles under potentiostatic conditions relevant to PEFC cathode conditions.

We have used transmission electron microscopy to determine the effect of pretreatment and potentiostatic voltage on the particle size of platinum electrocatalysts. Samples of commercially produced Pt/C cloth PEFC electrodes (E-Tek, $0.5 \mathrm{mg} \mathrm{Pt} / \mathrm{cm}^{2}$ ) were subjected to two different pretreatments and three different voltages in $0.57 \mathrm{M} \mathrm{HClO}_{4}$. The six samples were: 1) as-received; 2) Nafion ${ }^{\circledR}$-loaded (by impregnating the as-received carbon cloth with Nafion ${ }^{\circledR}$ solution); 3) Voltage cycled from 0 to 1.4 to $0 \mathrm{~V}$ at $10-50 \mathrm{mV} / \mathrm{s}$ until a stable cyclic voltammogram (CV) was obtained, usually after about 30 cycles; 4) $0.65 \mathrm{~V}$ sample, which was held at $0.65 \mathrm{~V}$ for $72 \mathrm{~h}$ after the $\mathrm{CV}$ was stable; 5) $1.4 \mathrm{~V}$ sample, which was held at $1.4 \mathrm{~V}$ for $72 \mathrm{~h}$ after the $\mathrm{CV}$ was stable; and 6) $0.9 \mathrm{~V}$ sample, which was subjected to 14 potentiostatic experiments where the sample was cycled until the $\mathrm{CV}$ was stable, and then held at $0.9 \mathrm{~V}$ for time periods ranging from 1 to $96 \mathrm{~h}$, for a total accumulated time of $467 \mathrm{~h}$ at $0.9 \mathrm{~V}$. These six samples were very finely cut apart and dispersed in isopropanol, allowing the $\mathrm{Pt} / \mathrm{C}$ electrocatalyst to be freed of the cloth fibers. During examination by TEM, it was found that the Pt particle diameters in the as-received sample and the Nafion ${ }^{\circledR}$-loaded sample were 1-3 nm with a few particles up to $\sim 5 \mathrm{~nm}$, as shown in Figure 1. In all of the other samples, there was an increase in the size for most of the particles, as well as a larger size distribution. Most of the Pt particles in these samples had diameters of from $2-5 \mathrm{~nm}$, but a few particles were as large at $10 \mathrm{~nm}$, as shown in Figures $2 \mathrm{a}$ and $\mathrm{b}$. The main conclusion drawn from the TEM study is that the Pt particles grew when potential was applied and that this growth occurred during the initial voltage cycling step of the electrochemical tests, which only lasts a few minutes, rather than during the $72+$ hours of potentiostatic exposure at $0.65 \mathrm{~V}, 0.9 \mathrm{~V}$, or $1.4 \mathrm{~V}$.

\section{References}

[1] J. Xie, et al., J. Electrochem. Soc., 152, A1011 (2005).

[2] R.M. Darling and J.P. Meyers, J. Electrochem. Soc., 126, A1523 (2003).

[3] E. Gülzow, J. Power Sources, 127, 213 (2004). 
[4] Research funded by the U.S. Department of Energy, Energy Efficiency and Renewable Energy, Hydrogen, Fuel Cells \& Infrastructure Technologies Program.

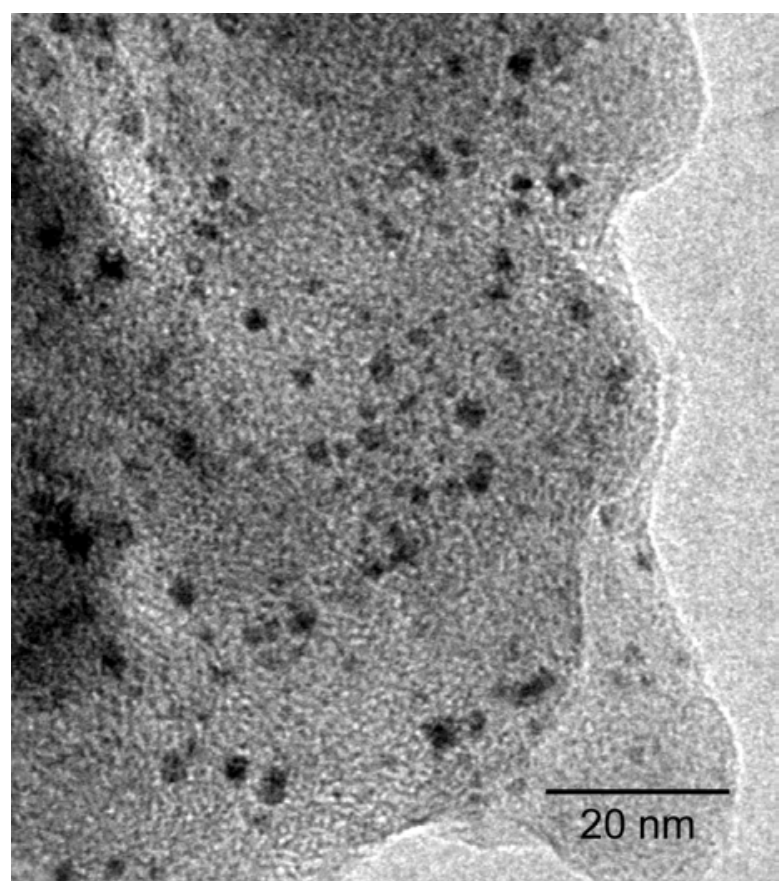

Figure 1. TEM image of the as-received platinum on carbon electrocatalyst that was imbedded in the electrode cloth. The platinum particles are $1-3 \mathrm{~nm}$ in diameter.
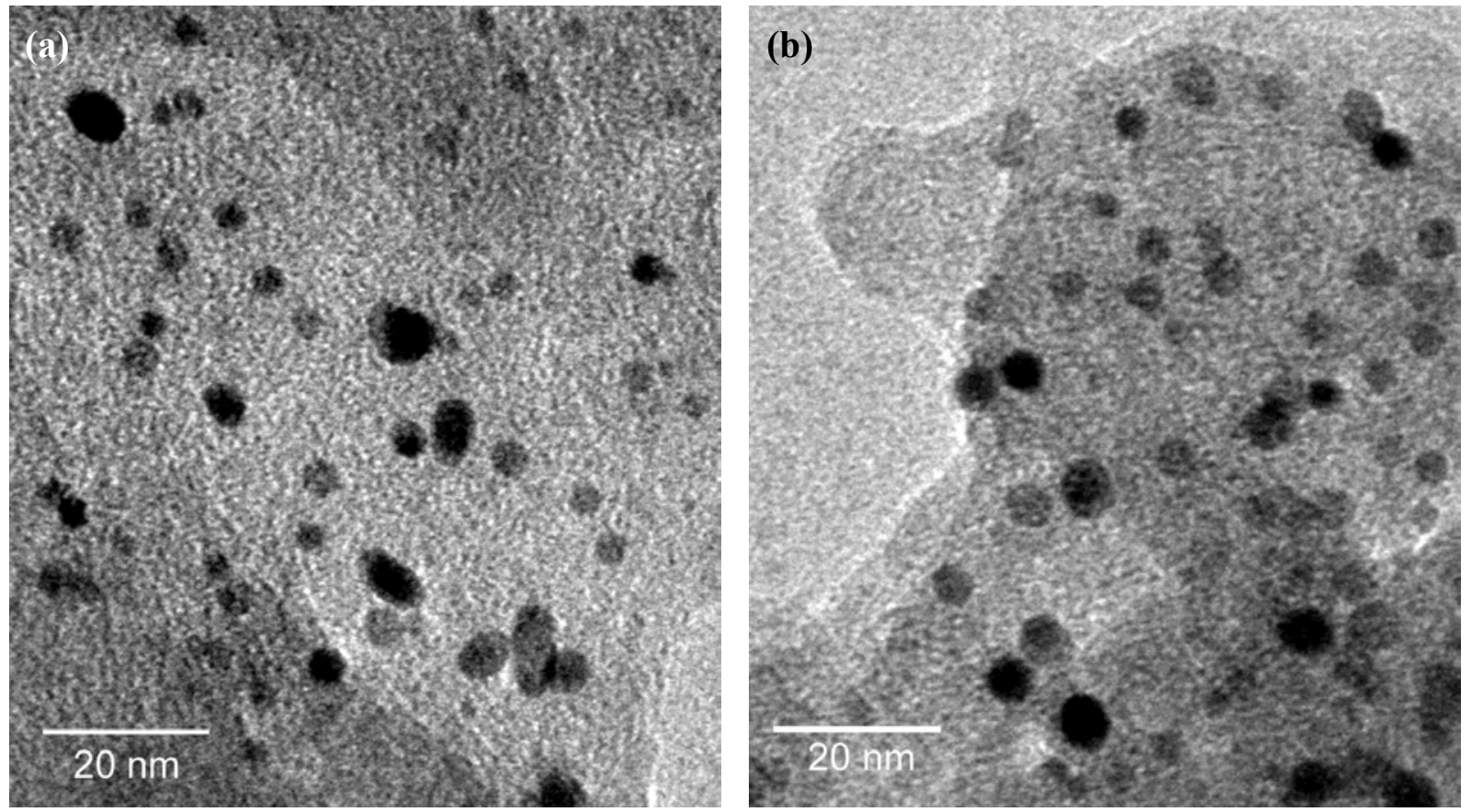

Figure 2. (a) TEM image of the Pt/C electrocatalyst after 30 voltage cycles. (b) TEM image of the $\mathrm{Pt} / \mathrm{C}$ electrocatalyst after voltage cycling and 467 hours of $0.9 \mathrm{~V}$ exposure.

The submitted manuscript has been created by the University of Chicago as Operator of Argonne National Laboratory (“Argonne") under Contract No. W-31-109-ENG-38 with the U.S. Department of Energy. The U.S. Government retains for itself, and others acting on its behalf, a paid-up, nonexclusive, irrevocable worldwide license in said article to reproduce, prepare derivative works, distribute copies to the public, and perform publicly and display publicly, by or on behalf of the Government. 